\title{
Bilgi ve Belge Yönetimi Bölümlerinde Öğrenci Profili
}

\author{
Student Profile of Information Management Departments
}

\section{S. Serap Kurbanoğlu*}

\begin{abstract}
Öz
Bu makalede, Türkiye'deki bilgi ve belge yönetimi bölümlerinin öğrenci profili üzerine yapılan bir çalışmanın bulguları sunulmuştur. Öğrenci profilinin belirlenmesi, öğrenci gereksinimlerine göre düzenlenmiş öğrenme ortamları hazırlanmasına ve ders programlarının gözden geçirilmesine katkıda bulunacaktır. Bulgular, Türkiye'deki dört bilgi ve belge yönetimi bölümünde kayıtı bulunan birinci sınıf öğrencilerinin \%60'dan fazlasının kız öğrenci olduğunu, öğrencilerin üniversiteye girerken yaptıkları ilk üç tercihleri arasında pedagoji bölümlerinin en çok tercih edilen bölümler olduğunu, öğrencilerin yaklaşık \%50’sinin kişisel bilgisayarı ve \%35'inin internet bağlantısı bulunduğunu; ayrıca öğrencilerin gerek yabancı dil gerekse bilgisayar okuryazarlığı becerilerinin farklı düzeylerde olduğunu göstermektedir.
\end{abstract}

Anahtar sözcükler: Öğrenci profili, Bilgi ve belge yönetimi bölümü, Kütüphanecilik eğitimi.

\begin{abstract}
In this paper, findings of a study, the main aim of which is to collect information about student profile of information management departments in Turkey, are presented. Information about student profile contributes to the preparation of learning environments adjusted
\end{abstract}

* Doç.Dr.; Hacettepe Üniversitesi Edebiyat Fakültesi Bilgi ve Belge Yönetimi Bölümü 06532 Beytepe-Ankara (serap@hacettepe.edu.tr). 
according to students' needs and the re-organization of curricula. The findings indicate that more than $60 \%$ of the students who enrolled in four information management departments are female. Percentage of pedagogy departments is the highest among the first three preferences of the students when they entered to the university. Around $50 \%$ of the students own personal computers and 35\% have Internet access. Students seems to have diversified levels of foreign language and computer literacy skills.

Keywords: Student profile, Information management department, Library education.

\section{Giriş}

Amaçları ve temel sorumlulukları "öğrencilerine mesleklerinin gerektirdiği ... bilgi, beceri ve teknik yetkinliği kazandırmak ve ... karşılaşabilecekleri mesleki sorunlara çözüm üretebilecek nitelikler ile donatılmalarına yardımcı olmak" (Çakın, 1999, s. 135) şeklinde tanımlanan bilgi ve belge yönetimi bölümlerinin değişen koşullar çerçevesinde, gerek yurt içinde gerekse yurt dışında, yeniden yapılanma çalışmaları yürüttükleri, bu çalışmalar sonucunda programlarını ve gerekli durumlarda adlarını değiştirme eğilimi gösterdikleri bilinmektedir (Çakın, 2000, s. 11).

Daha önce "kütüphanecilik" adı altında faaliyet gösteren bilgi ve belge yönetimi bölümlerimizin bu alandaki son çalışmaları yakın bir geçmişte gerçekleşmiş ve henüz ilk mezunlarını vermemiştir. Bilgi ve belge yönetimi adı altında, ortaöğretimin Türkçe-Matematik grubundan çıkışlı öğrencileri ÖSS'de aldıkları eşit ağırıkıı puan türüne göre kabul eden yeni program, Hacettepe (H.Ü.), Ankara (A.Ü.) ve İstanbul (İ.Ü.) Üniversitesiteleri'nde 2002-2003 eğitim öğretim yılında uygulamaya konulmuştur. Mevcut kütüphanecilik bölümlerinin Bilgi ve Belge Yönetimi (BBY) adı altında yeniden yapılanmasının yanı sıra Başkent Üniversitesi (B.Ü.) içinde de aynı adı taşıyan bir bölüm kurulmuş ve 2002-2003 yılından itibaren öğrenci kabul etmeye başlamıştır. Bu bölüm bir vakıf üniversitesinin Illetişim Fakültesi içinde yapılanması ve programı itibariyle diğer bölümlerden farklılıklar göstermektedir. 


\section{Çalışmanın Amacı ve Çalışma Grubu}

Çalışmanın amacı, gerek yeniden yapılanma çalışmalarının sonucunda Ankara, Hacettepe ve İstanbul Üniversitelerindeki BBY Bölümlerini, gerekse yeni kurulan Başkent Üniversitesi BBY Bölümünü tercih ederek bu bölümlere kayıt yaptıran öğrencilerin profilleri hakkında genel bilgi edinmek ve varsa bölümler arası farklılıkları ortaya çıkarmaktır. BBY bölümlerinde okuyan öğrenci profilinden elde edilen bilgilerin; ders programlarının yeniden düzenlenmesi, öğrenci gereksinimlerine uygun öğrenme ortamlarının hazırlanması gibi ileriye yönelik planlama çalışmalarına katkıda bulunacağı düşünülmektedir.

Çalışma, 2003-2004 eğitim-öğretim yılı güz döneminde yukarıda sözü edilen dört BBY bölümünün birinci sınıf öğrencileri üzerinde yürütülmüştür. Öğrencilerin bölümlere göre çalışmaya katılım oranları \%65 ile \%91,7 arasında değişmektedir (Bkz. Tablo 1). Sonuç olarak çalışmaya katılan öğrenci sayısı evreni temsil gücüne sahiptir.

Tablo 1. Araştırmaya Katılım Oranı

\begin{tabular}{lccc}
\hline & $\mathbf{N}$ & $\mathbf{n}$ & $\begin{array}{c}\text { Katılım } \\
\text { Oranı }\end{array}$ \\
\hline A.Ü & 60 & 39 & $\% 65,0$ \\
B.Ü. & 12 & 11 & $\% 91,7$ \\
H.Ü. & 86 & 64 & $\% 74,4$ \\
I.Ü. & 110 & 94 & $\% 85,5$ \\
Toplam & $\mathbf{2 6 8}$ & $\mathbf{2 0 8}$ & $\% 77,6$ \\
\hline
\end{tabular}

\section{Yöntem ve Veri Toplama Tekniği}

Çalışmada betimleme yöntemi ve veri toplama tekniği olarak anket kullanılmışıı*. Anket; öğrencilerin cinsiyetleri, yaşları, mezun oldukları lisenin türü, bölümlerini tercih sıraları, üniversiteye girerken yaptıkları ilk üç tercih, bilgisayarlar ve internet bağlantıları açısından sahip oldukları kişisel olanaklar, bilgisayar okuryazarlığı becerileri ve bir kütüphanede aradığını bulmak konusundaki becerileri üzerine toplam 24 soruyu içermektedir.

* Anketlerin uygulanmasında yardımcı olan meslektaşlarım Doç. Dr. Inci Önal, Doç. Dr. Fatoş Subaşıoğlu, Yrd. Doç. Dr. Mesut Yalvaç ve Mustafa Sağsan’a teşekkür ederim. 


\section{Bulgular ve Değerlendirme}

Öğrencilerin Genel Özellikleri

Araştırmaya katılan toplam 208 öğrenciden \%66,3'ü kız, \%33,7'si erkek öğrencidir. Bölümler ayrı ayrı ele alındığı zaman da benzer bir dağılım ortaya çıkmakta, kız öğrencilerin oranı \%60'ın üzerinde kalmaktadır. Hacettepe Üniversitesi BBY Bölümünde bu oranın \%71,9'a yükseldiği görülmektedir. Sonuç olarak BBY bölümlerinin kız öğrenciler tarafından daha çok tercih edildiği ve kız öğrenci sayısının erkek öğrenci sayısının yaklaşık iki katı olduğu söylenebilir (Bkz. Tablo 2).

Tablo 2. Öğrencilerin Cinsiyetlerine Göre Dağılımı

\begin{tabular}{|c|c|c|c|c|c|c|}
\hline & \multicolumn{2}{|c|}{$\mathrm{K} \mathbf{} \mathrm{z}$} & \multicolumn{2}{|c|}{ Erkek } & \multicolumn{2}{|c|}{ Toplam } \\
\hline & $\mathbf{n}$ & $\%$ & $\mathbf{n}$ & $\%$ & $\mathbf{n}$ & $\%$ \\
\hline A.Ü & 24 & 61,5 & 15 & 38,5 & 39 & 100,0 \\
\hline B.Ü. & 7 & 63,6 & 4 & 36,4 & 11 & 100,0 \\
\hline H.Ü. & 46 & 71,9 & 18 & 28,1 & 64 & 100,0 \\
\hline I.Ü. & 61 & 64,9 & 33 & 35,1 & 94 & 100,0 \\
\hline Toplam & 138 & 66,3 & 70 & 33,7 & 208 & 100,0 \\
\hline
\end{tabular}

Yaşlarına göre dağılımlarına bakıldığında, toplamda öğrencilerin yaklaşık \%80'inin 18 ile 20 yaş arasında olduğu (\%31,3'ü 19, \%26,4'ü 18, \%23,1'i 20 yaşında) görülmektedir. Öğrencilerin \%13'ü 21 yaşında, \%4,3'ü 21'in üzerinde, \%1,9'u ise 18'in altındadır. Bölümlere göre dağılımlar bazı farklılıklar göstermektedir. Ankara Üniversitesi BBY Bölümünde 18 ile 21 yaş arası yakın bir dağılım gösterirken (18 yaş \%20,5, 19 yaş \%25,6, 20 yaş $\% 20,5,21$ yaş \%28,2), Başkent Üniversitesi BBY Bölümünde 18 yaş $(\% 36,4)$, Hacettepe Üniversitesi BBY Bölümünde 19 ve 20 yaş (sırasıyla $\% 29,7$ ve \%34,4), İstanbul Üniversitesi BBY Bölümünde ise 18 ve 19 yaş $(\% 39,4$ ve \%36,2) dağılımda ağırlık kazanmaktadır. Hacettepe'de 18 yaş oranının diğer bölümlere göre düşük olması $(\% 9,4)$, öğrencilerin çoğunluğunun bir yıllık hazırlık eğitiminden geçmesi ile açıklanabilir. 18 yaş üniversiteye başlama yaşı olarak kabul edilirse eldeki veriler öğrencilerin \%26,4'ünün gecikmeksizin, \%31,3'ünün bir yıl gecikmeyle (söz konusu bir yıl, eğitim hayatlarının herhangi bir döneminde okudukları hazırlık sınıfından 
kaynaklanabilir), \%23,1'inin iki yıl gecikmeyle BBY bölümlerindeki eğitimlerine başladığını göstermektedir (Bkz. Tablo 3).

Tablo 3. Öğrencilerin Yaşlarına Göre Dağılımı

\begin{tabular}{rrrrrrrrrrr}
\hline Yaş & \multicolumn{1}{c}{ A.Ü. } & \multicolumn{2}{c}{ B.Ü. } & \multicolumn{2}{c}{ H.Ü } & \multicolumn{2}{c}{ i.Ü. } & \multicolumn{2}{c}{ Toplam } \\
\hline & n & $\%$ & n & $\%$ & n & $\%$ & n & $\%$ & n & $\%$ \\
\hline $\mathbf{1 7}$ & - & - & 1 & 9,1 & 1 & 1,6 & 2 & 2,1 & 4 & 1,9 \\
$\mathbf{1 8}$ & 8 & 20,5 & 4 & 36,4 & 6 & 9,4 & 37 & 39,4 & 55 & 26,4 \\
$\mathbf{1 9}$ & 10 & 25,6 & 2 & 18,2 & 19 & 29,7 & 34 & 36,2 & 65 & 31,3 \\
$\mathbf{2 0}$ & 8 & 20,5 & 1 & 9,1 & 22 & 34,4 & 17 & 18,1 & 48 & 23,1 \\
$\mathbf{2 1}$ & 11 & 28,2 & 1 & 9,1 & 13 & 20,3 & 2 & 2,1 & 27 & 13,0 \\
$\mathbf{2 2 +}$ & 2 & 5,1 & 2 & 18,2 & 3 & 4,7 & 2 & 2,1 & 9 & 4,3 \\
Toplam & $\mathbf{3 9}$ & $\mathbf{1 0 0 , 0}$ & $\mathbf{1 1}$ & $\mathbf{1 0 0 , 0}$ & $\mathbf{6 4}$ & $\mathbf{1 0 0 , 0}$ & $\mathbf{9 4}$ & $\mathbf{1 0 0 , 0}$ & $\mathbf{2 0 8}$ & $\mathbf{1 0 0 , 0}$ \\
\hline
\end{tabular}

Öğrencilerin mezun oldukları liselere bakılınca üç tür liseden geldikleri görülmektedir. 208 öğrencinin \%63,9'u genel veya süper lise mezunudur. $\% 24,5$ 'i Anadolu Liselerinden, \%11,5’i ise özel liselerden gelmektedir. Ankara Üniversitesi ve Hacettepe Üniversitesi BBY Bölümlerini tercih eden öğrencilerin \%70'den fazlası genel lise mezunudur (sırasıyla \%76,9 ve \%71,9). Bu oran İstanbul Üniversitesi'nde \%57,4'e ve Başkent'te \%27,3'e düşmektedir. Başkent Üniversitesi BBY Bölümü özel liselerden gelen öğrenci oranıyla $(\% 63,6)$ diğer üç bölümden farklııık gösterir. Özel liselerden gelen öğrencilerin vakıf üniversitelerine devam edebilecek koşullara sahip oldukları ve bu eğilimi gösterdikleri düşünülebilir. Anadolu Liselerinden mezun olan öğrencilerin BBY bölümlerini tercihlerine gelince, İstanbul Üniversitesi'nde birinci sınıf öğrencilerinin \%34'ünü, Hacettepe'de ise \%21,9'unu Anadolu Lisesi mezunlarının oluşturduğu görülmektedir. Bu oran Ankara Üniversitesi'nde \%10,3'e, Başkent'te ise \%9,1'e düşmektedir. Müfredatları gereği Anadolu Lisesi öğrencilerinin genel lise öğrencilerinden daha farklı donanımlarla mezun oldukları bilinmektedir. Bu öğrenciler için, aldıkları eğitim sayesinde yabancı dil becerilerini ve okullarının olanaklarına paralel olarak bilgisayar kullanma becerilerini lise yıllarında geliştirme olanakları bulunmaktadır (Bkz. Tablo 4). 
Tablo 4. Öğrencilerin Mezun Oldukları Lise Türüne Göre Dağılımı

\begin{tabular}{lrrrrrrrr}
\hline & \multicolumn{2}{c}{ Genel/Süper } & \multicolumn{2}{c}{ Anadolu } & \multicolumn{2}{c}{ Özel } & \multicolumn{2}{c}{ Toplam } \\
& \multicolumn{1}{c}{$\mathbf{n}$} & \multicolumn{1}{c}{$\%$} & \multicolumn{1}{c}{$\mathbf{n}$} & \multicolumn{1}{c}{$\%$} & \multicolumn{1}{c}{$\mathbf{n}$} & \multicolumn{1}{c}{$\%$} & \multicolumn{1}{c}{$\mathbf{n}$} & \multicolumn{1}{c}{$\%$} \\
\hline A.Ü & 30 & 76,9 & 4 & 10,3 & 5 & 12,8 & 39 & 100,0 \\
B.Ü. & 3 & 27,3 & 1 & 9,1 & 7 & 63,6 & 11 & 100,0 \\
H.Ü. & 46 & 71,9 & 14 & 21,9 & 4 & 6,3 & 64 & 100,0 \\
I.Ü. & 54 & 57,4 & 32 & 34,0 & 8 & 8,5 & 94 & 100,0 \\
Toplam & $\mathbf{1 3 3}$ & $\mathbf{6 3 , 9}$ & $\mathbf{5 1}$ & $\mathbf{2 4 , 5}$ & $\mathbf{2 4}$ & $\mathbf{1 1 , 5}$ & $\mathbf{2 0 8}$ & $\mathbf{1 0 0 , 0}$ \\
\hline
\end{tabular}

Öğrencilerin Tercihleri

Üniversiteye girerken yaptıkları tercihler arasında bulundukları bölümü tercih sıralarına gelince, öğrencilerin \%38,9'unun bulundukları BBY bölümünü ilk beş tercihleri arasına aldıkları görülmektedir. Dört bölüme ait veriler birlikte incelendiğinde öğrencilerin \%56,2'sinin bölümlerini ilk 10 tercihleri arasına yazdıkları, \%43,8'inin ise tercihleri arasında bulundukları bölüme 10. sıradan sonra yer verdikleri görülmektedir. Bölümlere ait veriler, ayrı ayrı incelendiğinde Başkent $(\% 63,7)$ ve Hacettepe (\%61) Üniversitelerindeki BBY Bölümlerine gelen öğrencilerin yarısından fazlasının bölümlerine ilk 5 tercihleri arasında yer verdikleri görülmektedir. Bu oran İstanbul Üniversitesi'nde \%29,8, Ankara Üniversitesi'nde ise \%17,9'dur (Bkz. Tablo 5).

Tablo 5. Öğrencilerin Bölümlerini Tercih Sırasına Göre Dağılımı

\begin{tabular}{|c|c|c|c|c|c|c|c|c|c|c|}
\hline \multirow{2}{*}{$\begin{array}{c}\text { Tercih } \\
\text { sırası }\end{array}$} & \multicolumn{2}{|c|}{ A.Ü. } & \multicolumn{2}{|c|}{ B.Ü. } & \multicolumn{2}{|c|}{ H.Ü } & \multicolumn{2}{|c|}{ İ.Ü. } & \multicolumn{2}{|c|}{ Toplam } \\
\hline & $\mathrm{n}$ & $\%$ & $\mathrm{n}$ & $\%$ & $\mathrm{n}$ & $\%$ & $\mathrm{n}$ & $\%$ & $\mathrm{n}$ & $\%$ \\
\hline $1-5$ & 7 & 17,9 & 7 & 63,7 & 39 & 61 & 28 & 29,8 & 81 & 38,9 \\
\hline 6-10 & 7 & 17,9 & - & - & 10 & 15,5 & 19 & 20,2 & 66 & 17,3 \\
\hline $11-15$ & 15 & 38,5 & 3 & 27,3 & 9 & 14,1 & 37 & 39,4 & 64 & 30,8 \\
\hline $16-20$ & 8 & 20,5 & 1 & 9,1 & 2 & 3,2 & 7 & 7,4 & 18 & 8,7 \\
\hline $21+$ & 2 & 5,1 & - & - & 4 & 6,2 & 3 & 3,2 & 9 & 4,3 \\
\hline Toplam & 39 & 100 & 11 & 100 & 64 & 100 & 94 & 100 & 208 & 100,0 \\
\hline
\end{tabular}


Öğrencilere uygulanan ankette üniversiteye girerken yaptıkları ilk üç tercih de sorulmuştur. ÖSS'de aldıkları puan ve puan türü tercihlerde belirleyici olmakla beraber BBY bölümlerinin öğrencilerin tercihleri arasındaki yerini görmek ve öğrencilerin en çok tercih ettikleri diğer alanları belirlemek açısından eldeki bulgular değer taşımaktadır. Gösterdikleri farklılıklardan dolayı burada önce bölümler ayrı ayrı ele alınacak sonra toplu bir değerlendirme yapılacaktır.

Ankara Üniversitesi BBY Bölümü birinci sınıf öğrencilerinin ilk üç tercihleri bir arada değerlendirildiğinde $(39 \times 3=117)$, tercihlerin \%34,19'unun sınıf öğretmenliği bölümlerine yöneldiği görülmektedir. Bunu \%12,82 ile BBY, \%11,11 ile okul öncesi öğretmenliği, \%7,69 ile Psikolojik Danışma ve Rehberlik (PDR) bölümleri izlemektedir. Daha sonra \%4,2 ile işletme, \%3,42 ile Türkçe öğretmenliği, Türk dili ve edebiyatı ve uluslararası ilişkiler bölümleri gelmektedir. Diğer bölümlerin tercih edilme oranları \%2,56 ve daha altındadır. Öğrencilerin birinci, ikinci ve üçüncü tercihlerindeki sıralamalar ayrı ayrı ele alınıp incelendiğinde birinci tercihlerde BBY \%5,13 ile sınıf öğretmenliği $(\% 33,33)$, psikolojik danışma ve rehberlik $(\% 15,38)$, okul öncesi öğretmenliği $(\% 7,69)$ ve Türk dili ve edebiyatı $(\% 7,69)$ bölümlerinden sonra 5. sıraya yerleşmektedir. İkinci ve üçüncü tercihlerde BBY, sınıf öğretmenliği bölümünden sonra ikinci sıradaki yerini korumaktadır. Sınıf öğretmenliği bölümü her üç tercihte de öğrencilerin yaklaşık üçte birinin yöneldiği bölüm olarak ön plana çıkmaktadır (Bkz. Tablo 6).

Başkent Üniversitesi BBY Bölümü birinci sınıf öğrencilerinin üniversiteye girerken yaptıkları ilk üç tercihleri bir arada incelendiğinde, \%27,27 ile BBY bölümlerinin başı çektiği, \%15,15 ile uluslararası ilişkilerin onu izlediği görülmektedir. Daha sonra \%9,09 ile psikolojik danışma ve rehberlik, hukuk ve iletişim bölümleri devreye girmektedir. Psikolojik danışma ve rehberlik dışında Ankara Üniversitesi'ndeki öğrencilerle Başkent öğrencilerinin tercihleri örtüşmemektedir. Tercihler ayrı ayrı incelendiğinde birinci ve ikinci tercihlerde ilk sırayı BBY bölümleri alırken, üçüncü tercihlerde uluslararası ilişkilerin öne çıktığı görülmektedir (Bkz. Tablo 7). 
Tablo 6. A.Ü. BBY Bölümü Öğrencilerinin Üniversiteye Girişte Illk ÜçTercihleri

\begin{tabular}{|c|c|c|c|c|c|c|c|c|}
\hline \multirow[t]{2}{*}{ Bölümler } & \multicolumn{2}{|c|}{ 1. Tercih } & \multicolumn{2}{|c|}{ 2. Tercih } & \multicolumn{2}{|c|}{ 3. Tercih } & \multicolumn{2}{|c|}{ Toplam } \\
\hline & $\mathbf{n}$ & $\%$ & $\mathbf{n}$ & $\%$ & $\mathrm{n}$ & $\%$ & $n$ & $\%$ \\
\hline Sınıf Öğretm. & 13 & 33,33 & 13 & 33,33 & 14 & 35,90 & 40 & 34,19 \\
\hline BBY & 2 & 5,13 & 6 & 15,38 & 7 & 17,94 & 15 & 12,82 \\
\hline Okul Öncesi Öğretm. & 3 & 7,69 & 5 & 12,82 & 5 & 12,82 & 13 & 11,11 \\
\hline Psikolojik Danış. ve Reh. & 6 & 15,38 & 3 & 7,69 & - & - & 9 & 7,69 \\
\hline Işletme & 1 & 2,56 & 1 & 2,56 & 3 & 7,69 & 5 & 4,27 \\
\hline Türkçe Öğretm. & 2 & 5,13 & 1 & 2,56 & 1 & 2,56 & 4 & 3,42 \\
\hline Türk Dili ve Ed. & 3 & 7,69 & 1 & 2,56 & - & - & 4 & 3,42 \\
\hline Uluslararası Illişkiler & 2 & 5,13 & - & - & 2 & 5,13 & 4 & 3,42 \\
\hline Maliye & 1 & 2,56 & 1 & 2,56 & 1 & 2,56 & 3 & 2,56 \\
\hline Sosyal Hizmetler & 1 & 2,56 & 2 & 5,13 & - & - & 3 & 2,56 \\
\hline $\begin{array}{l}\text { Çalışma Ekon.ve End. } \\
\text { Ilişkil. }\end{array}$ & 1 & 2,56 & 2 & 5,13 & - & - & 3 & 2,56 \\
\hline Ekonometri & - & - & 1 & 2,56 & 1 & 2,56 & 2 & 1,71 \\
\hline Hukuk & 2 & 5,13 & - & - & - & - & 2 & 1,71 \\
\hline Iktisat & - & - & - & - & 2 & 5,13 & 2 & 1,71 \\
\hline Kamu Yönetimi & - & - & 1 & 2,56 & 1 & 2,56 & 2 & 1,71 \\
\hline Psikoloji & 1 & 2,56 & - & - & - & - & 1 & 0,85 \\
\hline Felsefe & - & - & 1 & 2,56 & - & - & 1 & 0,85 \\
\hline Çevre Tasarımı & - & - & - & - & 1 & 2,56 & 1 & 0,85 \\
\hline Sosyoloji & - & - & 1 & 2,56 & - & - & 1 & 0,85 \\
\hline Üstün Zekalılar Öğretm. & 1 & 2,56 & - & - & - & - & 1 & 0,85 \\
\hline Tercih Belirtilmemiş & - & - & - & - & 1 & 2,56 & 1 & 0,85 \\
\hline Toplam & 39 & 100,0 & 39 & 100,0 & 39 & 100,0 & 117 & 100,0 \\
\hline
\end{tabular}


Tablo 7. B.Ü. BBY Bölümü Öğrencilerinin Üniversiteye Girişte İlk Üç Tercihleri

\begin{tabular}{|c|c|c|c|c|c|c|c|c|}
\hline \multirow[t]{2}{*}{ Bölümler } & \multicolumn{2}{|c|}{ 1. Tercih } & \multicolumn{2}{|c|}{ 2. Tercih } & \multicolumn{2}{|c|}{ 3. Tercih } & \multicolumn{2}{|c|}{ Toplam } \\
\hline & $\mathbf{n}$ & $\%$ & $\mathrm{n}$ & $\%$ & $\mathrm{n}$ & $\%$ & $\mathrm{n}$ & $\%$ \\
\hline BBY & 3 & 27,27 & 4 & 36,36 & 2 & 18,18 & 9 & 27,27 \\
\hline Uluslararası Illişkiler & 1 & 9,09 & 1 & 9,09 & 3 & 27,27 & 5 & 15,15 \\
\hline $\begin{array}{l}\text { Psikolojik Danış. ve } \\
\text { Reh. }\end{array}$ & 1 & 9,09 & 1 & 9,09 & 1 & 9,09 & 3 & 9,09 \\
\hline Hukuk & 1 & 9,09 & 1 & 9,09 & 1 & 9,09 & 3 & 9,09 \\
\hline Illetişim Tasarım & 2 & 18,18 & 1 & 9,09 & - & - & 3 & 9,09 \\
\hline Halkla Ilişkiler & 1 & 9,09 & - & - & 1 & 9,09 & 2 & 6,06 \\
\hline Radyo-Sinema-TV & - & - & 1 & 9,09 & - & - & 1 & 3,03 \\
\hline Sosyoloji & 1 & 9,09 & - & - & - & - & 1 & 3,03 \\
\hline Işletme & 1 & 9,09 & - & - & - & - & 1 & 3,03 \\
\hline Uluslararası Ticaret & - & - & 1 & 9,09 & - & - & 1 & 3,03 \\
\hline Tercih Belirtilmemiş & - & - & 1 & 9,09 & 3 & 27,27 & 4 & 12,12 \\
\hline Toplam & 11 & 100,00 & 11 & 100,00 & 11 & 100,00 & 33 & 100,00 \\
\hline
\end{tabular}

Hacettepe Üniversitesi BBY Bölümü birinci sınıf öğrencilerinin tercihlerine gelince, öğrencilerin ilk üç tercihleri bir arada değerlendirildiğinde $\% 19,79$ oranıyla BBY bölümlerinin başta yer aldığı, onu \%16,67 ile psikolojik danışma ve rehberlik, \%11,98 ile sınıf öğretmenliği bölümlerinin izlediği görülmektedir. Sonra sırasıyla sosyal hizmetler $(\% 7,29)$, okul öncesi öğretmenliği $(\% 4,69)$, hukuk $(\% 3,65)$ ve Aktüerya $(\% 3,65)$ bölümleri gelmektedir. Tercihler ayrı ayrı incelendiğinde birinci tercihlerde psikolojik danışma ve rehberliğin öne çıktığı, ikinci tercihlerde BBY ile psikolojik danışma ve rehberliğin aynı oranla birinci sırayı aldığı, üçüncü tercihlerde BBY'nin açık farkla öne geçtiği görülmektedir (Bkz. Tablo 8).

İstanbul Üniversitesi'ne, gelince öğrencilerin ilk üç tercihleri arasında \%12,41 oranıyla sınıf öğretmenliği ilk sırada yer almaktadır. Onu \%8,51 ile hukuk ve psikolojik danışma ve rehberlik bölümleri, \%7,09 ile işletme, $\% 6,74$ ile iktisat izlemektedir. BBY ve uluslararası ilişkiler \%4,96 ile 6. sırada yer almaktadır. Tercihler ayrı ayrı incelendiğinde birinci tercihler arasında 
Tablo 8. H.Ü. BBY Bölümü Öğrencilerinin Üniversiteye Girişte İlk Üç Tercihleri

\begin{tabular}{|c|c|c|c|c|c|c|c|c|}
\hline \multirow{2}{*}{ Bölümler } & \multicolumn{2}{|c|}{ 1.Tercih } & \multicolumn{2}{|c|}{ 2.Tercih } & \multicolumn{2}{|c|}{ 3.Tercih } & \multicolumn{2}{|c|}{ Toplam } \\
\hline & $\mathrm{n}$ & $\%$ & $\mathrm{n}$ & $\%$ & $\mathbf{n}$ & $\%$ & $\mathrm{n}$ & $\%$ \\
\hline BBY & 9 & 14,06 & 13 & 20,31 & 16 & 25,00 & 38 & 19,79 \\
\hline Psikolojik Danış. ve Reh. & 12 & 18,75 & 13 & 20,31 & 7 & 10,93 & 32 & 16,67 \\
\hline Sınıf Öğretm. & 7 & 10,93 & 8 & 12,50 & 8 & 12,50 & 23 & 11,98 \\
\hline Sosyal Hizmetler & 9 & 14,06 & 3 & 4,69 & 2 & 3,13 & 14 & 7,29 \\
\hline Okul Öncesi Öğretm. & 2 & 3,13 & 2 & 3,13 & 5 & 7,81 & 9 & 4,69 \\
\hline Aktüerya & 5 & 7,81 & 2 & 3,13 & - & - & 7 & 3,65 \\
\hline Hukuk & 4 & 6,25 & 2 & 3,13 & 1 & 1,56 & 7 & 3,65 \\
\hline Işletme & 2 & 3,13 & 1 & 1,56 & 1 & 1,56 & 4 & 2,08 \\
\hline Psikoloji & - & - & 1 & 1,56 & 3 & 4,69 & 4 & 2,08 \\
\hline Türk Dili ve Ed. & 2 & 3,13 & 1 & 1,56 & - & - & 3 & 1,56 \\
\hline Zihinsel Engelliler Öğretm. & 1 & 1,56 & 1 & 1,56 & 1 & 1,56 & 3 & 1,56 \\
\hline Sosyoloji & - & - & 1 & 1,56 & 1 & 1,56 & 2 & 1,04 \\
\hline Türkçe Öğretm. & 1 & 1,56 & 1 & 1,56 & - & - & 2 & 1,04 \\
\hline Kamu Yönetimi & 1 & 1,56 & - & - & 1 & 1,56 & 2 & 1,04 \\
\hline Moda Tasarımı & 1 & 1,56 & - & - & 1 & 1,56 & 2 & 1,04 \\
\hline Radyo-Sinema-TV & - & - & 1 & 1,56 & 1 & 1,56 & 2 & 1,04 \\
\hline Iktisat & - & - & 2 & 3,13 & - & - & 2 & 1,04 \\
\hline Işitme Engelliler Öğretm. & 1 & 1,56 & 1 & 1,56 & - & - & 2 & 1,04 \\
\hline Maliye & - & - & - & - & 1 & 1,56 & 1 & 0,52 \\
\hline $\begin{array}{l}\text { Çalışma Ekon.ve End. } \\
\text { Iliş̧il. }\end{array}$ & - & - & - & - & 1 & 1,56 & 1 & 0,52 \\
\hline Çocuk Gelişimi & - & - & 1 & 1,56 & - & - & 1 & 0,52 \\
\hline Ekonometri & 1 & 1,56 & - & - & - & - & 1 & 0,52 \\
\hline Felsefe & - & - & - & - & 1 & 1,56 & 1 & 0,52 \\
\hline Halkla Ilişkiler & - & - & 1 & 1,56 & - & - & 1 & 0,52 \\
\hline Sağlık Yönetimi & - & - & 1 & 1,56 & - & - & 1 & 0,52 \\
\hline Sanat Tarihi & - & - & - & - & 1 & 1,56 & 1 & 0,52 \\
\hline Uluslararası Iliş̧iler & 1 & 1,56 & - & - & - & - & 1 & 0,52 \\
\hline Tercih Belirtilmemiş & 5 & 7,81 & 8 & 12,50 & 12 & 18,75 & 25 & 13,02 \\
\hline Toplam & 64 & 100,0 & 64 & 100,0 & 64 & 100,0 & 192 & 100,0 \\
\hline
\end{tabular}


başta yine sınıf öğretmenliği $(\% 14,89)$, hukuk $(\% 10,64)$, psikolojik danışma ve rehberlik $(\% 10,64)$ ve uluslararası ilişkiler $(\%$ 8,51) gelmektedir. BBY $\% 4,26$ ile birinci tercihler arasında 7. sırada yer almaktadır. Íkinci tercihlerde BBY 5. sıraya yükselirken en çok tercih edilen üç bölümün değişmediği görülmektedir. Üçüncü tercihlerde en çok tercih edilen bölümlerin başına psikoloji $(\% 9,57)$, iktisat $(\% 8,51)$ ve sınıf öğretmenliği $(\% 7,45)$ geçerken BBY'nin yine 5. sırada olduğu görülmektedir (Bkz. Tablo 9).

Tablo 9. I.Ü. BBY Bölümü Öğrencilerinin Üniversiteye Girişte Illk Üç Tercihleri

\begin{tabular}{|c|c|c|c|c|c|c|c|c|}
\hline & \multicolumn{2}{|c|}{ 1. Tercih } & \multicolumn{2}{|c|}{ 2. Tercih } & \multicolumn{2}{|c|}{ 3. Tercih } & \multicolumn{2}{|c|}{ Toplam } \\
\hline & $\mathrm{n}$ & $\%$ & $\mathbf{n}$ & $\%$ & $\mathbf{n}$ & $\%$ & $\mathbf{n}$ & $\%$ \\
\hline Sınıf Öğretm. & 14 & 14,89 & 14 & 14,89 & 7 & 7,45 & 35 & 12,41 \\
\hline Hukuk & 10 & 10,64 & 10 & 10,64 & 4 & 4,26 & 24 & 8,51 \\
\hline Psikolojik Danış. ve Reh. & 10 & 10,64 & 10 & 10,64 & 4 & 4,26 & 24 & 8,51 \\
\hline Psikoloji & 6 & 6,38 & 5 & 5,32 & 9 & 9,57 & 20 & 7,09 \\
\hline İşletme & 7 & 7,45 & 7 & 7,45 & 5 & 5,32 & 19 & 6,74 \\
\hline Iktisat & 4 & 4,26 & 2 & 2,13 & 8 & 8,51 & 14 & 4,96 \\
\hline Uluslararası Illişkiler & 8 & 8,51 & 3 & 3,19 & 3 & 3,19 & 14 & 4,96 \\
\hline BBY & 4 & 4,26 & 5 & 5,32 & 4 & 4,26 & 13 & 4,60 \\
\hline Okul Öncesi Öğretm. & 4 & 4,26 & 3 & 3,19 & 3 & 3,19 & 10 & 3,55 \\
\hline Sosyoloji & 2 & 2,13 & 4 & 4,26 & 3 & 3,19 & 9 & 3,19 \\
\hline Çalışma Ekon.ve Endüstri İl. & 1 & 1,06 & 3 & 3,19 & 5 & 5,32 & 9 & 3,19 \\
\hline Kamu Yönetimi & 3 & 3,19 & 3 & 3,19 & 2 & 2,13 & 8 & 2,84 \\
\hline Türk Dili ve Ed. & 2 & 2,13 & 2 & 2,13 & 3 & 3,19 & 7 & 2,48 \\
\hline Maliye & 1 & 1,06 & 1 & - & 4 & 4,26 & 6 & 2,13 \\
\hline Reklamcılık & 3 & 3,19 & 2 & 2,13 & 1 & 1,06 & 6 & 2,13 \\
\hline Ekonometri & 1 & 1,06 & 3 & 3,19 & 1 & 1,06 & 5 & 1,77 \\
\hline Türkçe Öğretm. & 3 & 3,19 & 1 & - & - & - & 4 & 1,42 \\
\hline Ulaştırma ve Lojistik & 2 & 2,13 & 2 & 2,13 & - & - & 4 & 1,42 \\
\hline Siyaset Bilimi & - & - & 1 & 1,06 & 3 & 3,19 & 4 & 1,42 \\
\hline Radyo-Sinema-TV & 1 & 1,06 & 1 & 1,06 & 1 & 1,06 & 3 & 1,06 \\
\hline Tip & 1 & 1,06 & 1 & 1,06 & 1 & 1,06 & 3 & 1,06 \\
\hline Enformatik & 1 & 1,06 & 1 & 1,06 & - & - & 2 & 0,71 \\
\hline İletişim & 1 & 1,06 & 1 & 1,06 & - & - & 2 & 0,71 \\
\hline İşitme Engelliler Öğretm. & - & - & 1 & 1,06 & 1 & 1,06 & 2 & 0,71 \\
\hline Gazetecilik & - & - & 1 & 1,06 & - & - & 1 & 0,35 \\
\hline Görme Engelliler Öğretm. & 1 & 1,06 & - & - & - & - & 1 & 0,35 \\
\hline Hemşirelik & - & - & - & - & 1 & 1,06 & 1 & 0,35 \\
\hline Sosyal Hizmetler & 1 & 1,06 & - & - & - & - & 1 & 0,35 \\
\hline Tarih & - & - & - & - & 1 & 1,06 & 1 & 0,35 \\
\hline Tercih Belirtilmemiş & 3 & 3,19 & 7 & 7,45 & 20 & 21,28 & 30 & 0,35 \\
\hline Toplam & 94 & 100,0 & 94 & 100,0 & 94 & 100,0 & 282 & 100,0 \\
\hline
\end{tabular}


Öğrencilerin üniversiteye girerken yaptıkları ilk üç tercihleri incelendiğinde bölümler arasında bazı farklılıklar görülmesine rağmen, BBY bölümlerinin yanı sıra sınıf öğretmenliği, PDR, okul öncesi öğretmenliği bölümlerinin en çok tercih edilen bölümler olduğu ve bazı durumlarda bu bölümlerin açık farkla BBY bölümlerinin önüne geçtiği görülmektedir. Diğerlerinden farklı olarak Başkent Üniversitesi'nde PDR Bölümü, öğrencilerin ilk üç tercihleri arasında yer alan tek pedagoji bölümüdür.

Dört bölümden elde edilen veriler bir arada incelendiğinde toplam 208 öğrencinin yaptığı 624 tercihten \%15,71'inin sınıf öğretmenliği bölümlerine, \%12,02'sinin BBY bölümlerine, \%10,90'ının PDR bölümlerine yöneldiği görülmektedir. Sınıf öğretmenliği, PDR ve okul öncesi öğretmenliği dışında öğrencilerin ilk üç tercihleri arasında yer alan Türkçe öğretmenliği, işitme engelliler öğretmenliği, görme engelliler öğretmenliği, zihinsel engelliler öğretmenliği, üstün zekalılar öğretmenliği gibi başka eğitim bölümleri de vardır. Hepsi bir araya getirildiği zaman öğrencilerin ilk üç tercihleri arasında eğitim bölümlerinin oranı \%34,78'i bulmaktadır. BBY bölümlerinin öğrencilerin ilk üç tercihleri arasında yer alma oranı ise \%12,02'dir. Eğitim bölümlerinin öğrenciler tarafından öncelikli olarak tercih edilmesinin nedenleri söz konusu alanlarda istihdam sorunu olmaması ve öğrencilerin pedagoji alanına duydukları ilgi ile açıklanabilir. Başta sınıf öğretmenliği, psikolojik danışma ve rehberlik ve okul öncesi öğretmenliği olmak üzere ülkemizde eğitim personeli açığı bulunduğu bilinmektedir. Üniversiteden mezun oldukları zaman iş bulma kaygısı taşımayacaklarını bilmek öğrenciler açısından önemli bir motivasyon kaynağı olarak değerlendirilebilir.

\section{Öğrencilerin Bilgisayar Okuryazarlığı Düzeyleri}

BBY bölümlerine gelen öğrencilerin bilgisayar okuryazarlığı düzeyleri konusunda genel bilgi edinmek için ankette çeşitli sorular yöneltilmiştir. Elde edilen veriler sonucunda dört bölüm toplamında öğrencilerin yaklaşık yarısının (\%49) kişisel bilgisayarı olduğunu göstermektedir. Veriler bölümler bazında ele alındığında Hacettepe ve İstanbul Üniversiteleri öğrencilerinde \%50'lik oranın korunduğu, Başkentte bu oranın \%90,9'a çıktığı, Ankara Üniversitesi'nde ise \%30,8'e düştüğü görülmektedir. Kişisel bilgisayarı olması öğrencilerin bilgisayarı açma-kapama, dosya yaratma, program yük- 
leme gibi temel bilgisayar okuryazarlığı becerilerine ve temel bilgisayar terminoloji bilgisine sahip olduklarını göstermesi açısından önemlidir. Aynı şekilde öğrencilere kişisel internet bağlantıları olup olmadığı da sorulmuştur. 208 öğrenciden \%36,5'inin, diğer bir deyişle kişisel bilgisayarı olan 102 öğrenciden \%74,5'inin internet bağlantısı olduğu görülmektedir. Bölümlerin verileri ayrı ayrı değerlendirildiğinde Başkent Üniversitesi öğrencilerinin diğerlerine göre daha yüksek oranda (öğrencilerin \%81,8'inin, kişisel bilgisayarı olan öğrencilerin \%90'ının) bu olanağa sahip oldukları görülmektedir. Üniversitenin statüsü burslu okuyanlar dışındaki öğrencilerin maddi olanaklarının yerinde olmasını gerektirdiği düşünülürse bu veriler şaşırtıcı değildir. Nitekim, özel liselerden gelen öğrenci sayısıyla da Başkent öğrencilerinin bu alandaki olanakları doğrulanmıştır. Diğer BBY bölümlerinde internet bağlantısı olan öğrenci oranlarının Ankara Üniversite'sinde \%28,2 (kişisel bilgisayarı olan öğrencilerin \%91,7'si), Hacettepe Üniversitesi'nde \%37,5 (kişisel bilgisayarı olan öğrencilerin \%75'i), İstanbul Üniversitesi'nde \%34 (kişisel bilgisayarı olan öğrencilerin \%66,6'sı) olduğu görülmektedir (Bkz. Tablo 10). Öğrencilerin; internet kaynaklarına, hizmetlerine, olanaklarına, kullanımına ve terminolojisine aşina olup olmadıkları konusunda fikir verebileceği düşünülerek bu verilere çalışmada yer verilmiştir.

Tablo 10. Öğrencilerin Kişisel Olanakları

\begin{tabular}{|c|c|c|c|c|c|c|c|c|c|c|c|c|}
\hline & \multicolumn{6}{|c|}{ Bilgisayarı } & \multicolumn{6}{|c|}{ İnternet Bağlantısı } \\
\hline & \multicolumn{2}{|c|}{ Var } & \multicolumn{2}{|c|}{ Yok } & \multicolumn{2}{|c|}{ Toplam } & \multicolumn{2}{|c|}{ Var } & \multicolumn{2}{|c|}{ Yok } & \multicolumn{2}{|c|}{ Toplam } \\
\hline & $n$ & $\%$ & $\mathrm{n}$ & $\%$ & $\mathrm{n}$ & $\%$ & $\mathbf{n}$ & $\%$ & $\mathrm{n}$ & $\%$ & $\mathrm{n}$ & $\%$ \\
\hline$\overline{\text { A.Ü }}$ & 12 & 30,8 & 27 & 69,2 & 39 & 100,0 & 11 & 28,2 & 28 & 71,8 & 39 & 100,0 \\
\hline B.Ü. & 10 & 90,9 & 1 & 9,1 & 11 & 100,0 & 9 & 81,8 & 2 & 18,2 & 11 & 100,0 \\
\hline H.Ü. & 32 & 50,0 & 32 & 50,0 & 64 & 100,0 & 24 & 37,5 & 40 & 62,5 & 64 & 100,0 \\
\hline İ.Ü. & 48 & 51,1 & 46 & 48,9 & 94 & 100,0 & 32 & 34,0 & 62 & 66,0 & 94 & 100,0 \\
\hline Toplam & 102 & 49,0 & 106 & 51,0 & 208 & 100,0 & 76 & 36,5 & 132 & 63,5 & 208 & 100,0 \\
\hline
\end{tabular}

Öğrencilere, bilgisayarları ve internet bağlantıları olup olmadığının yanı sıra; bir kısmı kelime işlemcileri kullanmak ve bilgisayarda tablolar, grafikler yaratmak gibi temel; bir kısmı da programlama yapmak, veri tabanı oluşturmak, web sayfası tasarlamak gibi üst düzey olmak üzere bilgisayar okuryazarlığı 
becerileriyle ilgili bir dizi soru yöneltilmiş ve bunlardan hangilerini tek başlarına yapabildikleri, hangilerini yaparken yardıma gereksinim duyacakları ve hangilerini hiç yapmadıkları sorulmuştur. Bu bölümden elde edilecek veriler söz konusu konuları içeren derslerin planlanması açısından faydalı olacaktır.

Tablo 11. Öğrencilerin Bilgisayar Kullanma Becerileri

\begin{tabular}{|c|c|c|c|c|c|c|c|c|c|c|c|c|c|c|c|}
\hline & \multicolumn{5}{|c|}{ Kendim yapabilirim } & \multicolumn{5}{|c|}{ Yardıma Gereksinim Duyarım } & \multicolumn{5}{|c|}{ Bilmiyorum Hiç Yapmadım } \\
\hline & AÜ & BÜ & нÜ & iÜ & $\begin{array}{c}\text { Toplam } \\
\%\end{array}$ & AÜ & BÜ & нÜ & iü & $\begin{array}{c}\text { Toplam } \\
\%\end{array}$ & AÜ & BÜ & HÜ & IÜ & $\begin{array}{c}\text { Toplam } \\
\%\end{array}$ \\
\hline \multirow{2}{*}{$\begin{array}{l}\text { Kelime işlemcilerle } \\
\text { belge oluşturmak }\end{array}$} & 11 & 9 & 27 & 33 & 80 & 20 & 1 & 27 & 29 & 77 & 8 & 1 & 10 & 32 & 51 \\
\hline & & & & & $\% 38,5$ & & & & & $\% 37,0$ & & & & & $\% 24,5$ \\
\hline \multirow{2}{*}{$\begin{array}{l}\text { Bilgisayarda oyun } \\
\text { oynamak }\end{array}$} & 27 & 10 & 54 & 85 & 176 & 6 & 1 & 6 & 5 & 18 & 6 & - & 4 & 4 & 14 \\
\hline & & & & & $\% 84,6$ & & & & & $\% 8,7$ & & & & & $\% 6,7$ \\
\hline \multirow{2}{*}{$\begin{array}{l}\text { Veri tabanı } \\
\text { yaratmak }\end{array}$} & 2 & 4 & 7 & 8 & 21 & 12 & 1 & 14 & 33 & 60 & 25 & 6 & 43 & 53 & 127 \\
\hline & & & & & $\% 10,1$ & & & & & $\% 28,8$ & & & & & $\% 61,1$ \\
\hline \multirow{2}{*}{$\begin{array}{l}\text { Programlama } \\
\text { yapmak }\end{array}$} & 2 & 3 & 6 & 11 & 22 & 13 & 2 & 15 & 33 & 63 & 24 & 6 & 43 & 50 & 123 \\
\hline & & & & & $\% 10,6$ & & & & & $\% 30,3$ & & & & & $\% 59,1$ \\
\hline \multirow{2}{*}{$\begin{array}{l}\text { Tablolar, grafikler } \\
\text { yaratmak }\end{array}$} & 10 & 8 & 30 & 35 & 83 & 14 & 2 & 19 & 29 & 64 & 15 & 1 & 15 & 30 & 61 \\
\hline & & & & & $\% 39,9$ & & & & & $\% 30,8$ & & & & & $\% 29,3$ \\
\hline \multirow{2}{*}{$\begin{array}{l}\text { Internette chat } \\
\text { yapmak }\end{array}$} & 23 & 9 & 56 & 79 & 167 & 7 & 1 & 8 & 8 & 24 & 9 & 1 & - & 7 & 17 \\
\hline & & & & & $\% 80,3$ & & & & & $\% 11,5$ & & & & & $\% 8,2$ \\
\hline \multirow[t]{2}{*}{$\mathrm{E}$ - posta işlemleri } & 27 & 9 & 49 & 72 & 157 & 8 & 1 & 13 & 10 & 32 & 4 & 1 & 2 & 12 & 19 \\
\hline & & & & & $\% 75,5$ & & & & & $\% 15,4$ & & & & & $\% 9,1$ \\
\hline \multirow[t]{2}{*}{ Internette alışveriş } & 14 & 9 & 31 & 45 & 99 & 7 & 1 & 6 & 16 & 30 & 18 & 1 & 27 & 33 & 79 \\
\hline & & & & & $\% 47,6$ & & & & & $\% 14,4$ & & & & & $\% 38,0$ \\
\hline \multirow{2}{*}{$\begin{array}{l}\text { Internette } \\
\text { bankacılık işlemleri }\end{array}$} & 7 & - & 23 & 45 & 75 & 7 & - & 13 & 14 & 34 & 25 & 11 & 28 & 35 & 99 \\
\hline & & & & & $\% 36,1$ & & & & & $\% 16,3$ & & & & & $\% 47,6$ \\
\hline \multirow{2}{*}{$\begin{array}{l}\text { Web'de surf } \\
\text { yapmak }\end{array}$} & 21 & 8 & 44 & 57 & 130 & 4 & 1 & 9 & 14 & 28 & 14 & 2 & 11 & 23 & 50 \\
\hline & & & & & $\% 62,5$ & & & & & $\% 13,5$ & & & & & $\% 24,0$ \\
\hline \multirow{2}{*}{$\begin{array}{l}\text { Web'de bilgi } \\
\text { aramak }\end{array}$} & 28 & 10 & 54 & 56 & 148 & 5 & 1 & 6 & 12 & 24 & 6 & - & 4 & 26 & 36 \\
\hline & & & & & $\% 71,2$ & & & & & $\% 11,5$ & & & & & $\% 17,3$ \\
\hline \multirow{2}{*}{$\begin{array}{l}\text { Web sayfası } \\
\text { tasarlamak }\end{array}$} & 3 & 2 & 9 & 13 & 27 & 10 & 3 & 15 & 23 & 51 & 26 & 6 & 40 & 58 & 130 \\
\hline & & & & & $\% 13,0$ & & & & & $\% 24,5$ & & & & & $\% 62,5$ \\
\hline
\end{tabular}

Veriler incelendiğinde bilgisayarda oyun oynamak, internette chat yapmak, e-posta işlemleri, web'de sörf yapmak ve web'de bilgi aramak her bölümde, öğrencilerin yarısından fazlasının kendi başına yapabildiği işlemler olarak karşımıza çıkarken; veri tabanı yaratmak, programlama yapmak, web sayfası tasarlamak öğrencilerin bilmediği ve hiç yapmadığı işlemler olarak karşımıza çıkmaktadır. Burada önemli olan, ister en temel bilgisayar okuryazarlığı 
becerileri olsun, ister üst düzey bilgisayar okuryazarlığı becerileri olsun, oranlar değişmekle birlikte hemen her birini kendi başına yapabilen öğrenciler olduğu gibi, hiç bilmediğini ve hiç yapmadığını söyleyen öğrencilerin de olmasıdır (Bkz. Tablo 11). Söz konusu becerilerin bir kısmı, BBY bölümlerinde dersler kapsamında öğrencilere kazandırılmaya çalışılmaktadır. Burada önemli olan, farklı düzeylerde becerilere sahip olduğu görülen öğrencilere aynı programı sunmanın yaratacağı sorunlardır. Söz konusu becerilerin öğretildiği derslerde düzeyin hiç bilmeyene göre ayarlanması konu hakkında deneyimli öğrenciler için vakit kaybı olurken, düzeyin yüksek tutulması hiç bilmeyenlerin motivasyonunu kıracaktır. Eldeki bulgular artık öğrencilerin üniversitelere temel bilgisayar okuryazarlığı becerilerine sahip olarak geldiğini göstermektedir. Bilgisayar okuryazarlığı becerilerinin öğretildiği dersler programlanırken bu durumun göz önünde tutulması faydalı olacaktır.

\section{Öğrencilerin Kütüphane Kullanma Becerileri}

Öğrencilere tüm bu soruların yanı sıra kütüphane kullanımıyla ilgili iki soru yöneltilerek, bir kütüphanede aradıklarını bulabilme ve çevrim içi kütüphane katalogu kullanabilme konularındaki becerilerini belirtmeleri istenmiştir. Tüm bölümlerde bir kütüphanede aradığını bulabileceğini belirten öğrenci oranı \%60'ın üzerindedir. Birinci sınıfın, birinci dönemini henüz tamamlamış öğrenciler açısından bu sevindirici bir orandır. Öğrencilerin \%30'a yakın kısmı yardıma gereksinimi olacağını belirtmiştir. Ne aradıklarına bağlı olarak bu aşamada yardıma gereksinim duymaları olağandır. Bu soruya "bilmiyorum, hiç yapmadım” yanıtını veren öğrencilerin oranının oldukça düşük olması ise sevindiricidir (Bkz. Tablo 12).

Tablo 12. Öğrencilerin Kütüphanede Aradığını Bulma Becerileri

\begin{tabular}{lrrrrrrrr}
\hline & $\begin{array}{c}\text { Kendim } \\
\text { Yapabilirim }\end{array}$ & \multicolumn{2}{c}{$\begin{array}{c}\text { Yardıma Gereksinim } \\
\text { Duyarım }\end{array}$} & \multicolumn{2}{c}{$\begin{array}{c}\text { Bilmiyorum, Hiç } \\
\text { Yapmadım }\end{array}$} & \multicolumn{2}{c}{ Toplam } \\
\hline & $\mathbf{n}$ & $\%$ & $\mathbf{n}$ & $\%$ & $\mathbf{n}$ & $\%$ & $\mathbf{n}$ & $\mathbf{\%}$ \\
\hline A.Ü & 25 & 64,1 & 13 & 33,3 & 1 & 2,6 & 39 & 100 \\
B.Ü. & 8 & 72,7 & 2 & 18,2 & 1 & 9,1 & 11 & 100 \\
H.Ü. & 41 & 64,1 & 23 & 35,9 & - & - & 64 & 100 \\
I.Ü. & 61 & 64,9 & 21 & 22,3 & 12 & 12,8 & 94 & 100 \\
Toplam & $\mathbf{1 3 5}$ & $\mathbf{6 4 , 9}$ & $\mathbf{5 9}$ & $\mathbf{2 8 , 4}$ & $\mathbf{1 4}$ & $\mathbf{6 , 7}$ & $\mathbf{2 0 8}$ & $\mathbf{1 0 0}$ \\
\hline
\end{tabular}


Çevrim içi kütüphane kataloglarının kullanımı ile ilgili olarak sorulan soruya verilen yanıtlar incelendiğinde toplamda; öğrencilerin \%35,6'sının çevrim içi katalogları kendi başına kullanabileceğini, \%36,6'sının yardıma gereksinim duyacağını, \%28,8'inin ise çevrim içi katalogu hiç kullanmadığını belirttiği görülmektedir (Bkz. Tablo 13). Katalog kullanımı bir kütüphanede aradığını bulmakla doğrudan ilişkili olduğundan bir önceki soruya verilen yanıtlarla, bu soruya verilen yanıtların dağılım oranları arasında benzerlik olması beklenmektedir. Ancak, öğrencilerin ilgili iki soruya verdikleri yanıtların dağılım oranlarının farklı olduğu görülmektedir. Buradan, öğrencilerin bir kısmının kütüphanede aradığını katalog kullanmadan bulma yoluna gittiği anlamı çıkartılabilir.

Sonuç olarak, genelde çevrim içi katalog hiç kullanmadığını $(\% 28,8)$ ve kullanımı konusunda yardıma gereksinim duyduğunu belirten $(\% 35,6)$ öğrenci sayısının yüksek olduğu, birinci sınıfa başlayan öğrenciler için kütüphane oryantasyonu veya ilgili olabilecek herhangi bir dersin kapsamı içinde çevrim içi kataloglarda tarama yapma konusunun ele alınmasının faydalı olabileceği anlaşılmaktadır. Öğrencilerin bu alandaki becerilerinin erken geliştirmesi daha sonraki araştırma faaliyetlerini doğrudan etkileyeceği için önemlidir.

Tablo 13. Öğrencilerin Çevrim Içi Katalog Kullanma Becerileri

\begin{tabular}{lrrrrrrrr}
\hline & $\begin{array}{c}\text { Kendim } \\
\text { Yapabilirim }\end{array}$ & \multicolumn{2}{c}{$\begin{array}{c}\text { Yardıma Gereksinim } \\
\text { Duyarım }\end{array}$} & \multicolumn{2}{c}{$\begin{array}{c}\text { Bilmiyorum, Hiç } \\
\text { Yapmadım }\end{array}$} & \multicolumn{2}{c}{ Toplam } \\
\hline & $\mathbf{n}$ & $\%$ & $\mathbf{n}$ & $\%$ & $\mathbf{n}$ & $\%$ & $\mathbf{n}$ & $\boldsymbol{\%}$ \\
\hline A.Ü & 18 & 46,2 & 12 & 30,8 & 9 & 23,1 & 39 & 100,0 \\
B.Ü. & 8 & 72,7 & 2 & 18,2 & 1 & 9,1 & 11 & 100,0 \\
H.Ü. & 31 & 48,4 & 24 & 37,5 & 9 & 14,1 & 64 & 100,0 \\
l.Ü. & 17 & 18,1 & 36 & 38,3 & 41 & 43,6 & 94 & 100,0 \\
Toplam & $\mathbf{7 4}$ & $\mathbf{3 5 , 6}$ & $\mathbf{7 4}$ & $\mathbf{3 5 , 6}$ & $\mathbf{6 0}$ & $\mathbf{2 8 , 8}$ & $\mathbf{2 0 8}$ & $\mathbf{1 0 0 , 0}$ \\
\hline
\end{tabular}

\section{Sonuç ve Öneriler}

Eldeki bulgulardan BBY bölümlerinin daha çok kız öğrenciler tarafından tercih edildiği anlaşılmaktadır. Anadolu Liselerinden mezun olan öğrencilerin BBY bölümlerini tercih etmeleri sevindiricidir. BBY bölümlerine gelen öğren- 
cilerin ortaöğretimden getirdikleri bilgi ve beceri alt yapısı hiç kuşkusuz eğitimin kalitesini olumlu yönde etkileyecektir.

Öğrencilerin yaklaşık \%40'ının, bulundukları BBY bölümüne üniversiteye girerken yaptıkları ilk 5 tercih arasında yer verdikleri anlaşıımaktadır. Bu oran Hacettepe ve Başkent Üniversiteleri BBY Bölümlerinde \%60'ın üzerine çıkmaktadır. Bu durum, küçümsenmeyecek sayıda öğrencinin, bölümünü, ÖSS puanı ve puan türü ile tercih edebileceği bölümler arasından isteyerek seçtiğini göstermesi açısından önemlidir. İsteyerek seçtiği programa kayıt yaptıran öğrencilerden daha iyi verim alınması olasılığı da yüksektir.

Öğrencilerin üniversiteye girerken yaptıkları ilk üç tercihleri arasında eğitim bölümlerinin ağırlıklı olmasının nedenleri üzerinde durulmalıdır. Söz konusu alanlardaki eleman açığı nedeniyle öğrencilerin mezun olduklarında iş bulma kaygısıyla eğitim alanına yöneldikleri düşünülebilir. Bu durumda BBY bölümlerinden mezun olacak öğrencilerin iş olanakları ve çalışma alanları konularının tanıtımda ön plana çıkartılması faydalı olabilir.

Öğrencilerin alana ilgilerinden dolayı ilk üç tercihlerinde eğitim bölümlerine yer verdikleri de düşünülebilir. Kullanıcı eğitimi alanında yaşanan gelişmeler sonucunda, kütüphaneciler tarafından kullanıcılara verilen eğitimin kapsamı alabildiğine genişletilmiş, özellikle üniversite ve okul kütüphanecileri tarafından bilgi okuryazarlığı adı altında dersler verilmeye başlanmıştır. Bu derslerin planlanması, eğitim materyalinin hazırlanması, öğrencilerle iletişim, öğrencinin ve dersin başarısının ölçülmesi gereği, bu dersleri veren kütüphanecilerin/bilgi profesyonellerinin öğretim yöntem ve teknikleri, öğrenme kuramları, sınıf yönetimi, ölçme ve değerlendirme gibi pedagoji alanlarında bilgi ve deneyim sahibi olmalarını gerektirmektedir (Grassian ve Kaplowitz, 2001, s. 34; Oberman, 2002, ss. 1-5; Markless, 2002, ss. 1-4). BBY bölümlerine gelen öğrencilerin bir kısmının bu alana duydukları ilgi değerlendirilerek iki yönlü kazanım sağlanabilir. BBY bölümü öğrencileri için, seçmeli olarak açılacak pedagoji dersleri ile hem alana ilgi duyan öğrencilerin ilgisi değerlendirilmiş, hem de bilgi okuryazarlığı eğitimi için gereksinim duyulan insan gücü yetiştirilmiş olur.

Öğrencilerin mezun oldukları liselerin türü yabancı dil düzeyleri hakkında genel bilgi vermektedir. Özel liseler ve Anadolu Liselerinden mezun olan 
öğrencilerin genel liselerden mezun olan öğrencilere göre genelde daha iyi bir dil eğitimi aldıkları bilinmektedir. Bu durum, öğrencilerin yabancı dil düzeylerinin farklı olduğunu göstermektedir. Aynı şekilde eldeki verilerden öğrencilerin bilgisayar okuryazarlığı düzeylerinin de farklı olduğu anlaşılmaktadır. Gerek yabancı dil, gerekse bilgisayar okuryazarlığı ile ilgili dersler planlanırken, bu durumun göz önünde tutulması, düzeylere göre şubelendirme ve/veya belli bir düzeyin üzerindeki öğrencilerin derslerden muaf tutulması gibi seçenekler sunulması, bunlar yapılamıyorsa derslerin farklı düzeylerdeki öğrencilere hitap edebilecek şekilde düzenlenmesi önerilebilir. Bu durum başlangıç düzeyindeki öğrencilerle ileri düzeydeki öğrencilerin aynı sınıfta olmasından doğabilecek motivasyon kaybına engel olacaktır.

BBY bölümlerinin yeniden yapılanma çalışmalarının öğrenci profili üzerindeki yansımaları zaman içinde daha iyi ortaya çıkacaktır. Önümüzdeki 5-10 yıl içinde benzer çalışmaların yapılması ve sonuçların karşılaştırılması değişimleri izlemek açısından anlamlı olacağı gibi, gelecekte yürütülecek yeniden yapılanma çalışmalarına da ışık tutması açısından faydalı olacaktır.

\section{Kaynakça}

Çakın, I. (1999). Kütüphanecilik eğitimi ve yeni hedefler. Ö. Bayram, E. Erkan ve E. Yılmaz (Yay. Haz.), “21. Yüzyıla Doğru Türk Kütüphaneciliği”: 35. Kütüphane Haftası bildirileri: 15-21 Mart 1999 Ankara içinde (ss. 135146). Ankara: Türk Kütüphaneciler Derneği.

Çakın, I. (2000). Bilgi profesyonellerinin eğitiminde yeniden yapılanma: Hacettepe Üniversitesi örneği. Türk Kütüphaneciliği, 14, 3-17.

Grassian, E. S. ve Kaplowitz, J. R. (2001). Information literacy instruction: Theory and practice. New York: Neal-Schuman.

Markless, S. (2002, Ağustos). Learning about learning rather than about teaching. 68 $8^{\text {th }}$ IFLA Council and General Conference, Glasgow'da sunulan bildiri.

Oberman, C. (2002, Ağustos). What the ACRL institute for information literacy best practices initiative tells us about the librarian as teacher. $68^{\text {th }}$ IFLA Council and General Conference, Glasgow'da sunulan bildiri. 